\title{
Neonatal McCune-Albright syndrome with systemic involvement: a case report
}

\author{
Rita Lourenço ${ }^{1 *}$, Patrícia Dias², Raquel Gouveia ${ }^{1}$, Ana Berta Sousa ${ }^{2}$ and Graça Oliveira ${ }^{1}$
}

\begin{abstract}
Introduction: McCune-Albright syndrome is a rare sporadic disease characterized by fibrous bone dysplasia, café-au-lait skin spots and variable hyperfunctional endocrinopathies. McCune-Albright syndrome is caused by somatic postzygotic activating mutations in the GNAS gene that produce a broad spectrum of effects.

Case presentation: We report a case of McCune-Albright syndrome with multi-organ manifestations in the neonatal period. A newborn preterm black girl was referred to our Neonatal Intensive Care Unit at the age of 17 days for suspected extrahepatic cholestasis. On clinical examination she presented failure to thrive, jaundice, hypertension, marked hypotonia and café-au-lait spots on her back and lower limbs. An abdominal ultrasound excluded extrahepatic causes of cholestasis but revealed bilateral serpiginous adrenal hyperplasia. These clinical findings suggested a diagnosis of McCune-Albright syndrome with multi-organ involvement. Laboratory data confirmed adrenocorticotropic hormone-independent Cushing's syndrome, hyperthyroidism, cholestasis and elevated transaminases. Ventricular hypertrophy was demonstrated by echocardiography. The baby girl underwent medical treatment of Cushing's syndrome with metyrapone which was followed by a rapid recovery. A mosaic activating GNAS gene mutation was found on DNA extracted from a buccal swab sample. However, she died at 4 months due to a respiratory infection.
\end{abstract}

Conclusion: In the neonatal period the diagnosis of McCune-Albright syndrome depends on having a high index of suspicion and café-au-lait spots may be the clue for the diagnosis.

Keywords: Cushing's syndrome, GNAS gene mutations, McCune-Albright syndrome, Metyrapone

\section{Introduction}

McCune-Albright syndrome (MAS) is a rare sporadic disease characterized by bone fibrous dysplasia, caféau-lait (CAL) skin spots and a variable association of hyperfunctional endocrinopathies [1]. The estimated prevalence ranges between 1/100,000 and 1/1,000,000 [2].

MAS manifestations are due to somatic activating mutations in the GNAS gene which codes for the alpha subunit of the stimulatory G-protein (protein Gs $\alpha$ ) that is involved in intracellular cyclic adenosine monophosphate (cAMP) production [3]. A wide spectrum of extraskeletal manifestations can be found in MAS as would be expected from the broad tissue distribution of Gs $\alpha$ and the mosaic distribution of the mutation [4].

\footnotetext{
* Correspondence: ritadafonsecalourenco@gmail.com

${ }^{1}$ Neonatal Intensive-Care Unit, Department of Pediatrics, Hospital de Santa Maria, Centro Hospitalar Lisboa Norte, Centro Académico de Medicina de Lisboa, Lisbon, Portugal

Full list of author information is available at the end of the article
}

Cushing's syndrome may develop at any time in childhood but affects a minority of patients with MAS and has a quite heterogeneous natural history, ranging from spontaneous resolution to the need for adrenalectomy or even death [5].

Liver and cardiac diseases are additional less common extraskeletal manifestations of MAS and are markers of prognosis in children with Cushing's syndrome, which may suggest the need for prompt adrenalectomy [6].

Severe neonatal presentation of MAS is rare. We report a case of MAS in the neonatal period with multi-organ manifestations.

\section{Case presentation}

A 17-day-old black female neonate was referred to our Neonatal Intensive Care Unit (NICU) for suspected biliary atresia on the basis of cholestasis with acholia.

She was the first child of healthy non-consanguineous parents. Prenatal care was minimal. She was born at 35 
weeks and 5 days, weighing $1590 \mathrm{~g}$ (below third centile). Apgar scores were 8 and 9 at 1 and 5 minutes respectively. Jaundice was noted from the second day onwards and acholic stools were occasionally observed. Abdominal ultrasonography prompted concern for a choledochal cyst and apparent atresia. Hepatobiliary scintigraphy was performed but the results were inconclusive.

She also had a history of respiratory distress requiring oxygen therapy as well as hypertension treated with propranolol since day 14, at which an echocardiogram was reported as normal.

On clinical examination she was small for gestational age (length $39.5 \mathrm{~cm}$, weight $1545 \mathrm{~g}$, head circumference $28.5 \mathrm{~cm}$, all below the third centile). Her blood pressure was elevated $(118 / 90 \mathrm{mmHg}$, above the 95 th centile). She had marked hypotonia, well-defined CAL spots following Blaschko's lines on her back and lower limbs, heart murmur on cardiac auscultation and palpable liver edge $2.5 \mathrm{~cm}$ below the costal margin (Fig. 1).

\section{Outcome and investigations}

Laboratory findings confirmed cholestasis and abnormal liver function: total bilirubin $10.8 \mathrm{mg} / \mathrm{dL}$ (normal $<1 \mathrm{mg} / \mathrm{dL}$ ); conjugated bilirubin $9.5 \mathrm{mg} / \mathrm{dL}$ (normal $<0.3 \mathrm{mg} / \mathrm{dL}$ ); aspartate aminotransferase (AST) 211U/L (normal <34U/L); alanine aminotransferase (ALT) 623U/L (normal 12 to 78U/L); gamma-glutamyltransferase $(\gamma \mathrm{GT})$ 1219UI/L (normal <38UI/L); total cholesterol $343 \mathrm{mg} / \mathrm{dL}$ (normal $<190 \mathrm{mg} / \mathrm{dL}$ ); triglycerides $240 \mathrm{mg} / \mathrm{dL}$ (normal $<150 \mathrm{mg} / \mathrm{dL}$ ); total serum proteins, albumin, activated partial thromboplastin time, prothrombin time and fibrinogen were normal. Further investigations ruled out the most common causes of cholestasis (metabolic disease included in the neonatal screening, $\alpha 1$-antitrypsin deficiency, and cystic fibrosis). Because of ongoing cholestasis, ultrasonography of her abdomen was repeated; it demonstrated the absence

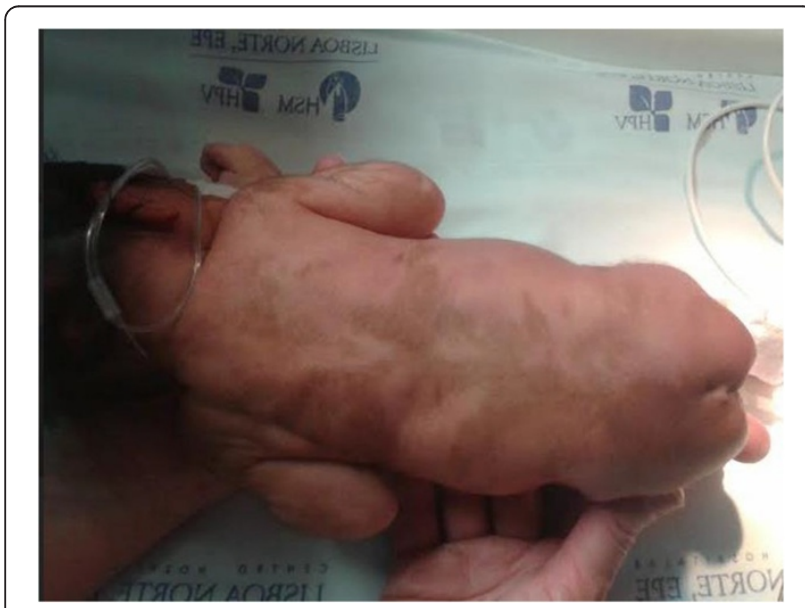

Fig. 1 Café-au-lait spots extending from the midline to lateral left and right dorsum, occupying most of its extension of a choledochal cyst and normal biliary tree but revealed bilateral serpiginous adrenal hyperplasia.

The association of abnormal skin pigmentation, cholestasis and adrenal hyperplasia led to genetic assessment and diagnosis of MAS.

A chest radiograph showed cardiomegaly. Repeated echocardiograms were performed revealing left ventricular hypertrophy, with initial thickness of the interventricular septum of 5.2mm (Z-Score 2.06) reaching a maximum of $7 \mathrm{~mm}$ (Z-Score 3.44). Systemic hypertension (systolic pressures 90 to $145 \mathrm{mmHg}$, diastolic pressures 55 to $105 \mathrm{mmHg}$ ) was confirmed. Primary renal disease was excluded by normal values of plasma renin activity and aldosterone, as well as renal imaging studies; her urinary catecholamines were normal. Echocardiography also documented the presence of pulmonary hypertension (systolic pulmonary artery pressure 55 to $60 \mathrm{mmHg}$ ) at 73 days of age, with progressive improvement until normalization.

As the baby presented markedly decreased muscle tone, growth restriction, hypertension and hyperglycemia (150 to $345 \mathrm{mg} / \mathrm{dL}$ ), other endocrine investigations were performed. Data showed hyperthyroidism: thyroid-stimulating hormone (TSH) $0.01 \mathrm{uU} / \mathrm{mL}$ (normal 0.5 to $6.0 \mathrm{uU} / \mathrm{mL}$ ); free thyroxine $\left(\mathrm{T}_{4}\right) 2.51 \mathrm{ng} / \mathrm{dL}$ (normal 0.8 to $1.76 \mathrm{ng} / \mathrm{dL}$ ); free triiodothyronine $\left(\mathrm{T}_{3}\right) 3 \mathrm{pg} / \mathrm{dL}$ (normal 2.3 to $4.2 \mathrm{pg} / \mathrm{dL}$ ). Levels of antithyroid antibodies were undetectable. Urinary free cortisol was increased (>75.0ug/dL/24 hours) and she had high serum cortisol without circadian variation (73.7ug/dL at 8 a.m., normal 4.3 to $23 ; 93.3 \mathrm{ug} / \mathrm{dL}$ at 11 p.m., normal 2.4 to $13.6 \mathrm{ug} / \mathrm{dL}$ ) and no suppression on high-dose dexamethasone $(108.4 \mathrm{ug} / \mathrm{dL})$. Her adrenocorticotropic hormone (ACTH) level was normal $(9.2 \mathrm{pg} / \mathrm{mL}$, normal 0 to $46 \mathrm{pg} / \mathrm{mL}$ ). These results were concordant with the diagnosis of ACTH-independent Cushing's syndrome.

A skeletal survey revealed generalized reduction of bone density, irregular ossification with areas of radiolucence surrounded by sclerosis most evident in her radius and ulna (Fig. 2).

Molecular diagnosis was possible in DNA extracted from a buccal swab sample, followed by amplification of the GNAS gene and direct sequencing. The activating mutation c.602G> A, leading to p. Arg201 to His, was identified in mosaic, confirming the clinical diagnosis of MAS.

\section{Treatment and follow-up}

The baby girl underwent medical treatment of Cushing's syndrome with metyrapone (six daily doses of $40 \mathrm{mg}$ ) from day 38 of age which was followed by rapid normalization of cortisol levels with glycemic and mean arterial pressure improvement (Fig. 3). Her growth velocity accelerated, producing gradual catch-up growth.

Her thyroid function was controlled with methimazole $1 \mathrm{mg} / \mathrm{kg}$ three times a day. 


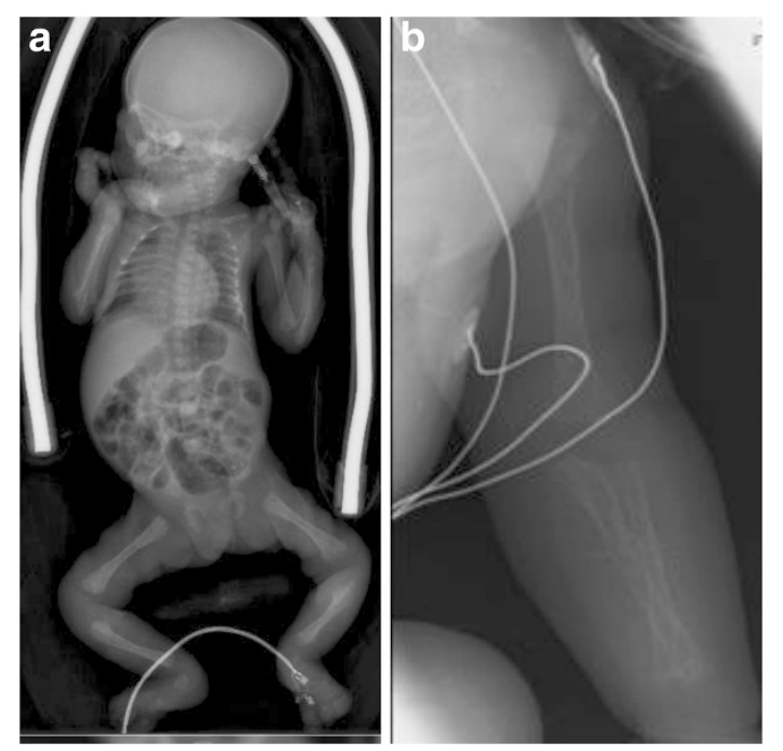

Fig. 2 a Radiographic appearance of bone fibrodysplasia. An important cardiomegaly is also observed. b Diaphyseal fracture of the ulna. In McCune-Albright syndrome fractures occur as a result of osteopenia associated with cortical thinning

Otherwise, her liver function test levels remained high (AST 709U/L, normal <34U/L; ALT 1656U/L, normal 12 to $78 \mathrm{U} / \mathrm{L}$; $\gamma \mathrm{GT} 1541 \mathrm{UI} / \mathrm{L}$, normal $<38 \mathrm{UI} / \mathrm{L}$; total bilirubin $7.65 \mathrm{mg} / \mathrm{dL}$, normal <1mg/dL; conjugated bilirubin $6.77 \mathrm{mg} /$ $\mathrm{dL}$, normal $<0.3 \mathrm{mg} / \mathrm{dL}$; total cholesterol $534 \mathrm{mg} / \mathrm{dL}$, normal <190mg/dL; triglycerides 198U/L mg/dL, normal <150mg/ dL). A trial of phenobarbital and ursodeoxycholic acid was initiated in an effort to stimulate bile flow, but jaundice persisted.

Hyperglycemia required insulin infusion from day 37 to day 47 of life and normalized after Cushing's syndrome control.
Hypertension control required the combination of two antihypertensive agents (propranolol and captopril) but normalized only after the introduction of metyrapone. Her echocardiogram showed a decrease in ventricular hypertrophy.

She had developmental delay with no apparent vision or hearing impairment. Magnetic resonance imaging showed hypoplasia of the cerebellar vermis.

The baby girl remained hospitalized due to oxygen dependence. At 4 months she was transferred to the Pediatric Intensive Care Unit for acute respiratory failure in the context of a pulmonary infection leading to her death. No infectious agent was isolated.

An anatomopathological examination was performed. Macroscopic observation of her habitus internus (internal general physical appearance) revealed lungs with increased consistence compatible with pneumonia, heart with biventricular hypertrophy, liver with chronic congestion abnormalities and increased weight, and cortical suprarenal increased thickness. Her ovary abnormalities were most remarkable, with her right ovary $3 \mathrm{~cm}$ long and her left ovary replaced by a cystic formation of $5.5 \mathrm{~cm}$ greater diameter (Fig. 4). At microscopic examination, micronodular hyperplasia of the adrenal glands confirmed the etiology of Cushing's syndrome (Fig. 5).

\section{Discussion}

Cushing's syndrome is the rarest of endocrine abnormalities found in MAS, and is caused by activation of Gs $\alpha$ in the adrenal cortex, leading to cortisol overproduction. Its prevalence in patients with fibrous dysplasia registered at the National Institutes of Health (NIH) was 7.1\% [6]. Its occurrence in the neonatal period causes severe growth failure, poor muscle tone, muscular hypoplasia and hypertension; it is associated with increased and early mortality due to

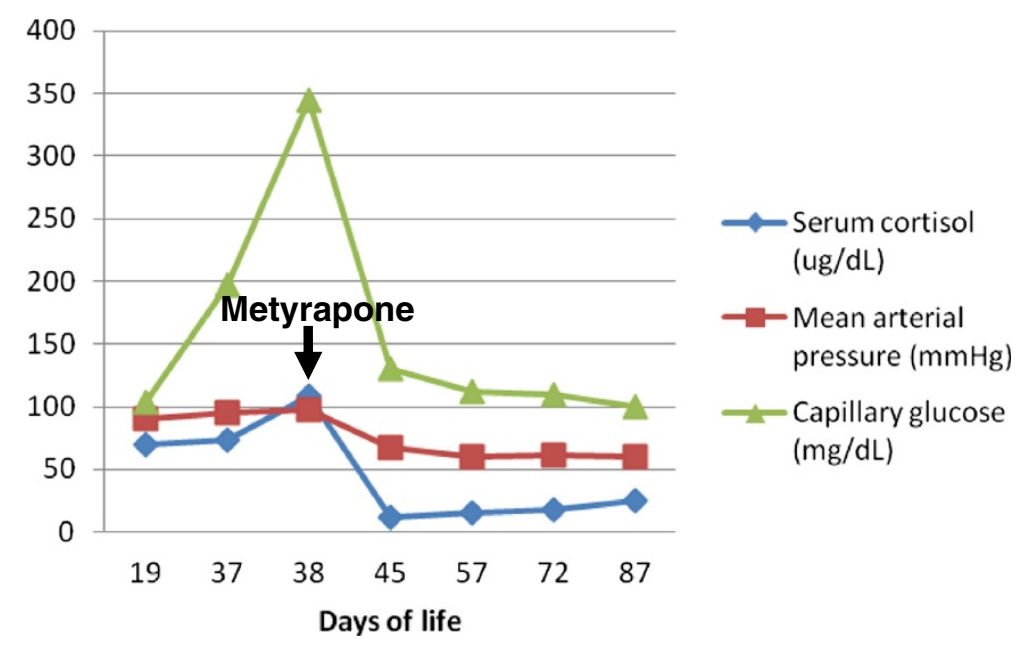

Fig. 3 Metyrapone effectiveness in the control of serum cortisol 


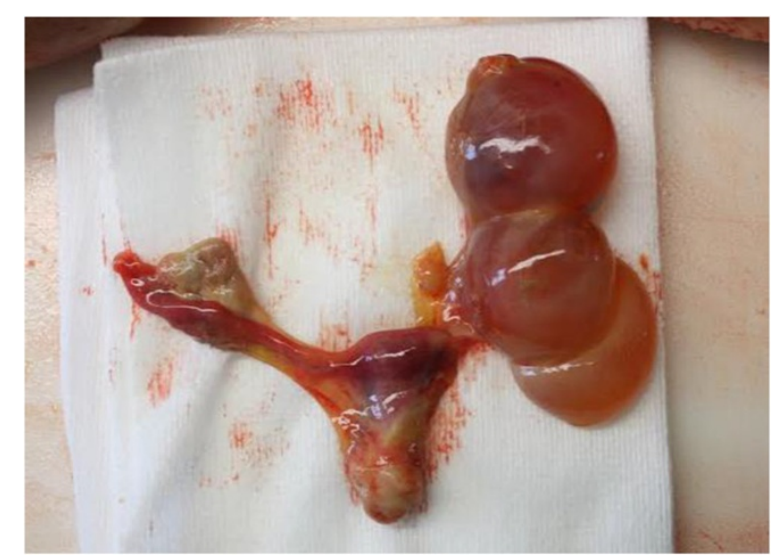

Fig. 4 Left ovary substituted by cystic formation. Enlargement of right ovary

opportunistic infections, hence the importance of prophylactic treatment, notably for Pneumocystis species [7].

Brown et al. reviewed all the published cases of Cushing's syndrome in MAS $(n=30)$ and listed the following signs and symptoms: small for gestational age (50\%), round facies $(66.7 \%)$, failure to thrive (60\%), hypertension (33.3\%), nephrocalcinosis (30\%), hirsutism (26.6\%), hyperglycemia $(20 \%)$, and linear growth arrest (10\%). Additional clinical features included liver disease, such as cholestasis or elevated transaminases (36.7\%), and heart disease, such as cardiomyopathy (26.7\%) [6].

In the present case, Cushing's syndrome is likely to have manifested in utero, since the baby was born small for gestational age and profound hypotonia most probably as a result of prolonged exposure to hypercortisolism. The triad of failure to thrive, hypertension and hyperglycemia is the result of adrenal gland hyperplasia leading to high levels of serum cortisol. It is also possible that her comorbidities, such as hyperthyroidism and heart disease, contributed to her failure to gain weight.

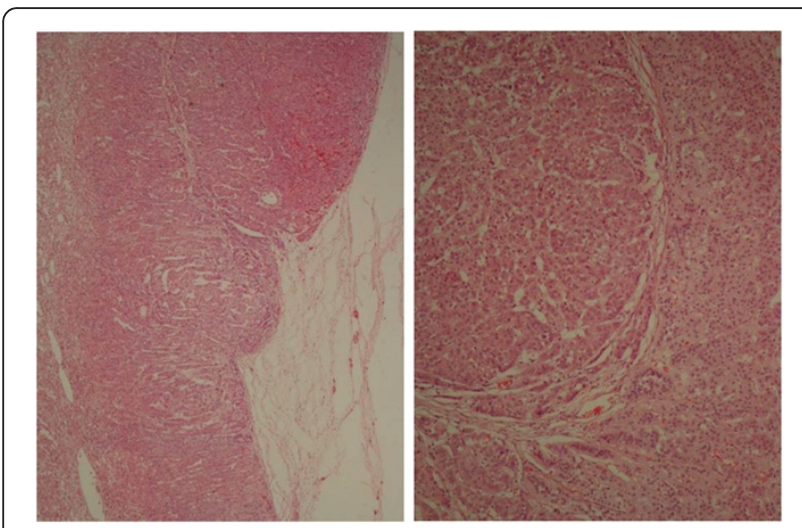

Fig. 5 Microscopic examination confirmed micronodular hyperplasia at adrenal glands
Although Cushing's syndrome can resolve spontaneously, many cases necessitate medical or surgical treatment $[5,6]$. No long-term effective medical treatment for ACTHindependent Cushing's syndrome is available. It is difficult to recognize which patients could safely be monitored and treated medically and which could benefit from adrenalectomy. We decided for medical treatment with metyrapone as our patient had cholestatic hepatitis that contraindicated the use of ketoconazole. In particularly sick children, medical treatment with metyrapone may gain time until the child is healthy enough for surgery [7]. Metyrapone was effective and well tolerated (Fig. 3). Therefore we agree with other authors that it is probably most appropriate to treat with metyrapone until a child is a suitable candidate for surgery.

Long-term sequelae of Cushing's syndrome in MAS comprise a significantly increased prevalence of cognitive disorders, including specific learning or speech disorders such as speech apraxia, and global developmental delay [6]. These children need developmental follow-up.

A case-control analysis of patients with MAS with and without Cushing's syndrome revealed that the presence of Cushing's syndrome was correlated with an increased number of clinical features of MAS, such as CAL spots, precocious puberty, hyperthyroidism, cognitive disorders and total number of MAS manifestations [6]. An alternative explanation is that mutated Gso is present in multiple organs as part of the mosaic MAS distribution, with Cushing's syndrome signaling a greater total body mutation burden and consequently associating with more severe phenotypes.

In fact, Cushing's syndrome usually occurs in patients with MAS with significant involvement of multiple other tissues. Table 1 represents the previously reported cases of Cushing's syndrome in patients with MAS associated with heart and liver disease, as described in the presented case.

CAL spots are typically the first manifestation of the disease, appearing usually either at or shortly after birth [7]. As such, they can be an early clue to the diagnosis of MAS. Classically, CAL spots have irregular borders (often described as similar to the coast of Maine). To what extent the size of spots correlates to the extent of disease is controversial.

The presence of the Gs $\alpha$ mutation in thyroid tissue results in ligand-independent activation of the TSH/G-protein/cAMP pathway, which is known to result in both hyperplasia and hyperfunction [8]. In addition, the Gs $\alpha$ mutation results in increased $T_{4}$ to $T_{3}$ conversion, which accounts for the $\mathrm{T}_{3}$-dominant biochemical phenotype of patients with MAS with hyperthyroidism [9]. Although the development of thyroid cancer is rare, patients should be monitored with annual thyroid ultrasound [10]. Spontaneous resolution rate is impossible to predict, so some form of treatment must be initiated. In our patient, her hyperthyroidism responded quite well to methimazole. 
Table 1 Reported cases of McCune-Albright syndrome with Cushing's syndrome, hepatobiliary and cardiovascular disease

\begin{tabular}{|c|c|c|c|c|c|c|}
\hline Sex & Age & $\begin{array}{l}\text { Cushing's } \\
\text { syndrome }\end{array}$ & Liver disease & Heart disease & Treatment/Outcome & Reference \\
\hline $\mathrm{F}$ & 37 days & + & Elevated LFTs & Cardiomegaly & Death (heart failure age 132 days) & [11] \\
\hline M & $\begin{array}{l}10 \\
\text { months }\end{array}$ & + & $\begin{array}{l}\text { Elevated LFTs, direct } \\
\text { hyperbilirubinemia }\end{array}$ & $\begin{array}{l}\text { Cardiomegaly, low } \\
\text { ejection fraction, } \\
\text { hypertension }\end{array}$ & $\begin{array}{l}\text { Aminoglutethimide and metyrapone until age } 2 \text { years. } \\
\text { Adrenalectomy at } 2 \text {-years old. Death from cardiac arrest at } \\
\text { age } 3 \text { years }\end{array}$ & [12] \\
\hline $\mathrm{F}$ & $\begin{array}{l}2 \\
\text { months }\end{array}$ & + & $\begin{array}{l}\text { Elevated LFTs, direct } \\
\text { hyperbilirubinemia }\end{array}$ & $\begin{array}{l}\text { Left ventricular } \\
\text { hypertrophy }\end{array}$ & $\begin{array}{l}\text { Adrenalectomy at } 3 \text { months. Death at age } 2 \text { years from } \\
\text { anaphylaxis and/or adrenal insufficiency }\end{array}$ & [12] \\
\hline M & $\begin{array}{l}10 \\
\text { weeks }\end{array}$ & + & Hepatomegaly & Cardiomegaly & NR & [13] \\
\hline $\mathrm{F}$ & 17 days & + & $\begin{array}{l}\text { Elevated LFTs, direct } \\
\text { hyperbilirubinemia, } \\
\text { hepatomegaly }\end{array}$ & $\begin{array}{l}\text { Left ventricular } \\
\text { hypertrophy }\end{array}$ & Metyrapone. Death from pneumonia at age 4 months & $\begin{array}{l}\text { Presented } \\
\text { case }\end{array}$ \\
\hline
\end{tabular}

$F$ female, LFTs liver function tests, $M$ male, NR not reported

Hepatobiliary dysfunction is included in the nonendocrine abnormalities associated with MAS and although it appears to be a rare manifestation, severe neonatal cholestasis and persistent elevated serum liver enzymes have been described [11-14]. The mechanism by which activated Gs $\alpha$ might cause hepatobiliary dysfunction remains unknown.

Hepatitis is more pronounced after birth, has laboratory manifestations consistent with cholestasis, progressively wanes with age but usually persists into adulthood (albeit mild) and is virtually never associated with a functional defect in the synthesis of important hepatic factors [14]. Both extra and intrahepatic bile ducts were patent in our patient, confirming that the defect lies at the level of the hepatocyte and/or biliary canalicular membrane, with the abnormal protein possibly interfering with the secretion of normal biliary components. The outcome of liver disease in previously described patients is not known [12].

Weinstein et al. demonstrated that cardiac Gs $\alpha$ mutation is more likely to be found in patients with extensive disease. Sudden death, tachycardia, ventricular hypertrophy, high-output heart failure and aortic root dilatation have all been reported in association with MAS [3]. It is not known whether it is a direct result of the presence of a primary cardiac Gs $\alpha$ mutation, or a secondary physiologic response to increased metabolic demand by hypercortisolism, hyperthyroidism and/or growth hormone excess. In this patient hypertension control required the association of two antihypertensives but it was only when Cushing's syndrome was treated that the patient achieved the appropriate mean arterial pressure and myocardial hypertrophy reduced.

Respiratory distress was due to multiple factors, such as prematurity and a high cardiac output. Control of the hypercortisolism did not improve respiratory function; although this was not previously described in the literature, perhaps pulmonary involvement was also the result of Gs $\alpha$ mutation in the lungs.

\section{Conclusion}

The diagnosis of MAS with Cushing's syndrome depends on having a high index of suspicion and CAL spots may be the clue for the diagnosis. In these patients rapid assessment for significant comorbidities should be performed, including hyperthyroidism, cardiac and liver disease. Evaluation for complications of the hypercortisolism should also be conducted, including hypertension and hyperglycemia, and hypercortisolism needs to be medically managed until definitive therapy. We conclude that the poor outcome of Cushing's syndrome in this group reflects a greater burden of mutation-carrying cells.

\section{Learning points}

- Cushing's syndrome in the neonatal period may suggest a diagnosis of MAS.

- CAL skin pigmentation in neonates must lead to the consideration of MAS in the differential diagnosis.

- Neonatal cholestasis is rarely associated with MAS.

- Multiple endocrine abnormalities should alert the clinician to the possibility of MAS.

- Families should be counseled that MAS is sporadic and displays no known environmental association or predilection for ethnic group.

\section{Consent}

Written informed consent was obtained from the patient's legal guardian(s) for publication of this case report and any accompanying images. A copy of the written consent is available for review by the Editor-in-Chief of this journal.

\section{Abbreviations}

ACTH: Adrenocorticotropic hormone; ALT: Alanine aminotransferase; AST: Aspartate aminotransferase; CAL: Café-au-lait; CAMP: Cyclic adenosine monophosphate; үGT: Gamma-glutamyltransferase; Gsa: Alpha subunit of the stimulatory G-protein; MAS: McCune-Albright syndrome; $T_{3}$ : Triiodothyronine; $\mathrm{T}_{4}$ : Thyroxine; TSH: Thyroid-stimulating hormone.

\section{Competing interests}

The authors declare that they have no competing interests. 
Authors' contributions

All the authors contributed to the work up of the patient including clinical evaluation, investigation and treatment planning. The manuscript has also been reviewed and approved by all authors.

\section{Acknowledgements}

We thank Dr Emília Vitorino for providing the information and photos of the anatomopathological examination.

\section{Author details}

'Neonatal Intensive-Care Unit, Department of Pediatrics, Hospital de Santa Maria, Centro Hospitalar Lisboa Norte, Centro Académico de Medicina de Lisboa, Lisbon, Portugal. ${ }^{2}$ Genetics Service, Department of Pediatrics, Hospital de Santa Maria, Centro Hospitalar Lisboa Norte, Centro Académico de Medicina de Lisboa, Lisbon, Portugal.

Received: 11 April 2015 Accepted: 21 August 2015

Published online: 04 September 2015

\section{References}

1. Albright F, Butler AM, Hampton AO, Smith P. Syndrome characterized by osteitis fibrosa disseminata, areas of pigmentation and endocrine dysfunction with precocious puberty in females. N Eng J Med 1937;216:727-46

2. Dumitrescu CE, Collins MT. McCune-Albright syndrome. Orphanet J Rare Dis. 2008:3:12

3. Weinstein LS, Shenker A, Gejman PV, Merino MJ, Friedman E, Spiegel AM. Activating mutations of the stimulatory $\mathrm{G}$ protein in the McCune-Albright syndrome. N Engl J Med. 1991;325:1688-95.

4. Happle R. The McCune-Albright syndrome: a lethal gene surviving by mosaicism. Clin Genet. 1986;29:321-4.

5. Kirk JM, Brain CE, Carson DJ, Hyde JC, Grant DB. Cushing's syndrome caused by nodular adrenal hyperplasia in children with McCune-Albright syndrome. J Pediatr. 1999;134:789-92.

6. Brown RJ, Kelly MH, Collins MT. Cushing syndrome in the McCune-Albright syndrome. J Clin Endocrinol Metab. 2010;95:1508-15.

7. Collins MT, Singer FR, Eugster E. McCune-Albright syndrome and the extraskeletal manifestations of fibrous dysplasia. Orphanet J Rare Dis. 2012;7 Suppl 1:S4. Epub 2012 May.

8. Combest WL, Russell DH. Alteration in cyclic AMP-dependent protein kinases and polyamine biosynthetic enzymes during hypertrophy and hyperplasia of the thyroid in the rat. Mol Pharmacol. 1983;23:641-7.

9. Celi FS, Coppotelli G, Chidakel A, Kelly M, Brillante BA, Shawker T, et al. The role of type 1 and type $25^{\prime}$-deiodinase in the pathophysiology of the 3,5,3 triiodothyronine toxicosis of McCune-Albright syndrome. J Clin Endocrino Metab. 2008:93:2383-9.

10. Collins MT, Sarlis NJ, Merino MJ, Monroe J, Crawford SE, Krakoff JA, et al. Thyroid carcinoma in the McCune-Albright syndrome: contributory role of activating Gs alpha mutations. J Clin Endocrinol Metab. 2003;88:4413-7.

11. Yoshimoto M, Nakayama M, Baba T, Uehara Y, Niikawa N, Ito M, et al. A case of neonatal McCune-Albright syndrome with Cushing syndrome and hyperthyroidism. Acta Paediatr Scand. 1991;80:984-7.

12. Shenker A, Weinstein LS, Moran A, Pescovitz OH, Charest NJ, Boney CM, et al. Severe endocrine and nonendocrine manifestations of the McCune-Albright syndrome associated with activating mutations of stimulatory G protein GS. J Pediatr. 1993;123(4):509-18.

13. Davies JH, Barton JS, Gregory JW, Mills C. Infantile McCune-Albright syndrome. Pediatr Dermatol. 2001;18:504-6.

14. Silva ES, Lumbroso S, Medina M, Gillerot Y, Sultan C, Sokal EM. Demonstration of McCune-Albright mutations in the liver of children with high gammaGT progressive cholestasis. J Hepatol. 2000;32:154-8.

\section{Submit your next manuscript to BioMed Central and take full advantage of:}

- Convenient online submission

- Thorough peer review

- No space constraints or color figure charges

- Immediate publication on acceptance

- Inclusion in PubMed, CAS, Scopus and Google Scholar

- Research which is freely available for redistribution

Submit your manuscript at www.biomedcentral.com/submit 